\title{
Development of Hepatozoon caimani (Carini, 1909) Pessôa, De Biasi \& De Souza, 1972 in the Caiman Caiman c. crocodilus, the Frog Rana catesbeiana and the Mosquito Culex fatigans
}

\author{
Ralph Lainson/ ${ }^{+}$, Ilan Paperna*, Roberto D Naiff**
}

\begin{abstract}
Departamento de Parasitologia, Instituto Evandro Chagas, Avenida Almirante Barroso 492, 66090-000 Belém, Pará, Brasil *Department of Animal Sciences, Faculty of Agricultural, Food and Environmental Quality Sciences, Hebrew University of Jerusalem, Rehovot, Israel **Coordenação de Pesquisas em Ciências da Saúde, Instituto Nacional de Pesquisa da Amazônia, Manaus, AM, Brasil
\end{abstract}

The sporogony of Hepatozoon caimani has been studied, by light microscopy, in the mosquito Culex fatigans fed on specimens of the caiman Caiman c. crocodilus showing gametocytes in their peripheral blood. Sporonts iniciate development in the space between the epithelium of the insect gut and the elastic membrane covering the haemocoele surface of the stomach. Sporulating oocysts are clustered on the gut, still invested by the gut surface membrane. Fully mature oocysts were first seen 21 days after the blood-meal. No sporogonic stages were found in some unidentified leeches fed on an infected caiman, up to 30 days following the blood-meal. When mosquitoes containing mature oocysts were fed to frogs (Leptodactylus fuscus and Rana catesbeiana), cysts containing cystozoites developed in the internal organs, principally the liver. Feeding these frogs to farm-bred caimans resulted in the appearance of gametocytes in their peripheral blood at some time between 59 and 79 days later, and the development of tissue cysts in the liver, spleen, lungs and kidneys. Transmission of the parasite was also obtained by feeding young caimans with infected mosquitoes and it is suggested that both methods occur in nature. The finding of similar cysts containing cystozoites in the semi-aquatic lizard Neusticurus bicarinatus, experimentally fed with infected C. fatigans, suggests that other secondary hosts may be involved.

Key words: Hepatozoon caimani - life-cycle - Caiman c. crocodilus - Caiman c. yacare - Melanosuchus niger - caimans - Rana catesbeiana - Leptodactylus fuscus - frogs - Culex fatigans - Brazil

For many years, all haemogregarines recorded in the blood of crocodilians were assigned to the genus Haemogregarina under the following specific names: $\mathrm{Hg}$. hankini Simond, 1901 of the Indian ghavial Gavialis gangeticus; Hg. crocodilinorum Börner, 1901 in Crocodylus acutus and Alligator mississipiensis from North America; Hg. caimani Carini, 1909 in Caiman latirostris from Brazil; Hg. pettiti Thiroux, 1910 in Cr. niloticus from Africa; Hg. serrei Phisalix, 1914 of Paleosuchus trigonatus from South America; $\mathrm{Hg}$. sheppardi Santos Dias, 1952 in Cr. niloticus from Africa; and unnamed species of Haemogregarina in Cr. porosus from Sri Lanka and Cr. palustris from Sumatra (Wenyon 1926, Levine 1988).

Chatton and Roubaud (1913) described the sporogony of an Hepatozoon sp., in wild-caught tsetse-flies, Glossina palpalis, in Africa and suspected that the parasite originated from either a lizard or a crocodile on which the insects had fed. It remained for Hoare (1932), however, to show that similar multisporocystic oocysts developed in laboratory-bred G. palpalis fed on Cr. niloticus that had

Work supported by grant no. 049426 from the Wellcome Trust, London (RL).

${ }^{+}$Corresponding author. Fax: +55-91-226.1284. E-mail: ralphlainson@iec.pa.gov.br

Received 23 July 2002

Accepted 19 September 2002 haemogregarines in their blood. As a result he amended the name of the parasite to Hepatozoon pettiti (Thiroux 1910). In recent years the suggestion has been made that all crocodilian haemogregarines should be transferred to the genus Hepatozoon (Siddall 1995, Smith 1996), although $H$. pettiti and $H$. caimani appear be be the only parasites for which there is supportive evidence from the demonstration of the sporogonic stages, characteristic of that genus (Hoare, 1932, Pessôa et al. 1972).

Lainson (1977) recorded haemogregarines in the erythrocytes of 46 of 60 (76.7\%) young Caiman c. crocodilus (Linn. 1758) from Bragança, State of Pará, North Brazil, diagnosed as a species of Hepatozoon by its sporogonic cycle in experimentally infected Culex fatigans. No infections were seen in 14 juvenile specimens of another caiman, Paleosuchus trigonatus, but morphologically similar blood forms have been noted in the black caiman, Melanosuchus niger, from Pará (Lainson, unpublished observations).

In the present communication we report our studies on the life-cycle of $H$. caimani of $C$. c c crocodilus, involving the experimental infection of the mosquito $C$. fatigans, wild-caught and farmed frogs (Leptodactylus fuscus and Rana catesbeiana, respectively) and caimans that had been bred in captivity.

\section{MATERIALS AND METHODS}

Natural infection in the caimans, C. c. crocodilus and C. c. yacare - Blood was obtained by clipping a claw or by heart puncture and thin smears air-dried, fixed in 
absolute methyl alcohol and stained by Giemsa's method. Two infected C. c. crocodilus showing abundant haemogregarines in the erythrocytes were sacrificed, and impression smears of liver, spleen, lungs and kidney stained by the same method. Pieces of these tissues were fixed in $10 \%$ buffered neutral formalin for histology. Similar material was obtained from six specimens of C. c. yacare from the State of Mato Grosso.

Development in mosquitoes - C. fatigans used in these experiments were from laboratory-bred colonies of mosquitoes originating from the outskirts of Belém, Pará, North Brazil: they were maintained at a temperature of from 24$26^{\circ} \mathrm{C}$. During the period $1992-1998$ we fed a total of eight separate batches of these mosquitoes on restrained, infected caimans for the purpose of separate studies on the sporogonic cycle of $H$. caimani and experimental transmission to caimans and intermediate hosts.

For the sporogonic cycle, fully fed mosquitoes were dissected at 1, 2-3, 6, 9 and $12 \mathrm{~h}$ post feeding and the guts and contained blood clot smeared, fixed in methyl alcohol and stained by Giemsa's method. The remaining mosquitoes were periodically dissected in order to follow development of the oocysts in fresh coverslip preparations. For histology, some guts were fixed entire in 10\% buffered neutral formalin, embedded in glycol metacrylate medium (GMA medium of Agar Scientific Ltd) and cut at 2-3 $\mu \mathrm{m}$ with a glass knife on a Sorval JB4 microtome: sections were stained with haematoxylin and eosin. Further material was fixed for transmission electron microscopy.

Development in the frogs Leptodactylus fuscus and Rana catesbeiana - In 1995, three wild-caught L. fuscus and three farm-bred $R$. catesbeiana were force-fed with batches of infected $C$. fatigans at 23 and 22 d.p.i. respectively, and in 1998 a further 10 R. catesbeiana were fed with other infected mosquitoes at 23 d.p.i. Some frogs were killed with chloroform at periods ranging from 14 to 28 d.p.i. and fresh, squash preparations of pieces of liver were examined under coverslips. Giemsa-stained dab smears were prepared from the liver, lungs, spleen and kidney. Some of the $R$. catesbeiana were retained for further observations and transmission experiments.

Transmission to caimans - Juvenile, uninfected caimans were obtained from the "Crocodile Safari" Zoological Gardens, on the outskirts of Belém, where they had been raised from eggs. They were maintained in an insectscreened animal house, on a diet of new-born laboratory white mice.

Transmission via the frog $R$. catesbeiana - Six of the frogs that had been fed with heavily infected mosquitoes in 1998 were sacrificed 30 d.p.i. and, following the detection of cysts in their livers, fed entire to six farm-bred caimans: blood films of these were periodically checked for the appearance of haemogregarines. Two of the caimans were killed 13 and 14 d.p.i., smears of liver, spleen, lung, kidney and the small intestine stained by Giemsa's method, and pieces of these tissues fixed in $10 \%$ buffered neutral formalin for histology. The surviving four animals were reserved for further observations.

Transmission via infected mosquitoes - Two farm-bred C. c. crocodilus were each force-fed with four C. fatigans from a batch of mosquitoes shown to have large numbers of mature oocysts at 23 d.p.i. They were retained for periodic examination of their blood for the appearance of gametocytes.

Photomicrographs were prepared using a Zeiss "Photomicroscope III" and Kodak TMX 100 film. All measurements are given in $\mu \mathrm{m}$, followed by the range in parentheses.

\section{RESULTS}

Natural infection in the caiman, C. c. crocodilus and C. c. yacare-Characteristic of the genus, the gametocytes of $H$. caimani show no sexual dimorphism and are restricted to the mature erythrocytes. They are enclosed in a capsule, which may or may not be strongly stained (Fig. 1), and from which occasional extracellular parasites can be seen to be emerging (Fig. 2). The larger intracellular gametocytes measure approximately $12.15 \times 4.3(10 \mathrm{x}$ $3.75-13.75 \times 3.75$ ), (50 measured) and have a dense, intensely staining nucleus placed somewhat laterally in the parasite: less frequently it may be in the form of a widely dispersed reticulum (Fig. 5). Within their capsule the gametocytes are doubled up on themselves (Fig. 4) giving them a sausage-like appearance. Extracellular forms, however, appear as long, slim bodies, measuring 20.7 x 3 $(16.2 \times 2.5-25 \times 4)(25$ measured). They are only occasionally found in blood films (Figs 2,3) and are best seen in the bloodmeal of mosquitoes recently fed on infected caimans (Fig. 16). Erythrocytes containing a single, mature gametocyte are rarely enlarged, but their nucleus is pushed to a lateral or polar position (Fig. 1): erythrocytes containing two, or even three parasites undergo some enlargement and deformation (Fig. 6).

No schizonts were detected in stained smears of the liver, spleen, lungs and kidney of the eight naturally infected caimans examined, but scanty to abundant monozoic and dizoic cysts were found in all of these tissues (Figs 7-9), predominantly in the liver. They measured 14.6 × $10(12.5$. $6.25-21.5 \times 21)(25$ measured $)$ and the contained zoites $12.5 \times 3.7(10 \times 1.25-15 \times 4)$.

Development in the mosquito - Extra-erythrocytic gametocytes were readily detected in the smears of mosquito guts made from 1-12 $\mathrm{h}$ after these insects had fed on infected caimans (Fig. 16). In one smear made at $12 \mathrm{~h}$ the nucleus of a few elongate gametocytes, and other spherical forms, was divided into 2-4 portions (Figs 17, 18), but we were unable to detect stages typical of the adeleid association of male and female parasites, the production of gametes and the process of fertilization. A fresh coverslip preparation of a dissected mosquito gut made at 11 d.p.i. showed young, uninucleate sporonts under the elastic membrane on the outer surface of the midgut (Fig. 19), and Giemsa-stained smears made at 13 and 14 d.p.i. contained others with early nuclear division (Figs 20,21). In fresh preparations made at this time there appeared the first signs of elevations on the surface of some parasites (Fig. 22), later to be thrown into the bulb-like protrusions into which the dividing nuclei migrate during formation of the sporocysts (Fig. 23).

Although developing sporozoites were seen in some sporocysts at 18 d.p.i, completely mature oocysts (Fig. 24) were first seen in dissected mosquitoes 21 d.p.i. and 
were crowded in large numbers in the haemocoele, on the surface of the intestine (Fig. 26). They measured up to $260 \mu \mathrm{m}$ in diameter and possessed a delicate, colourless oocyst wall enclosed by the elevated elastic membrane of the midgut surface (Figs 24, 25). The largest seen con- tained an estimated 80-100 spherical sporocysts, but no apparent residuum. Sporocysts varied from 20-30 in diameter and contained an estimate of from 12-24 crescentic sporozoites budded off from a conspicuous residual body, rather like a hand of bananas (Figs 27, 28). Living sporo-

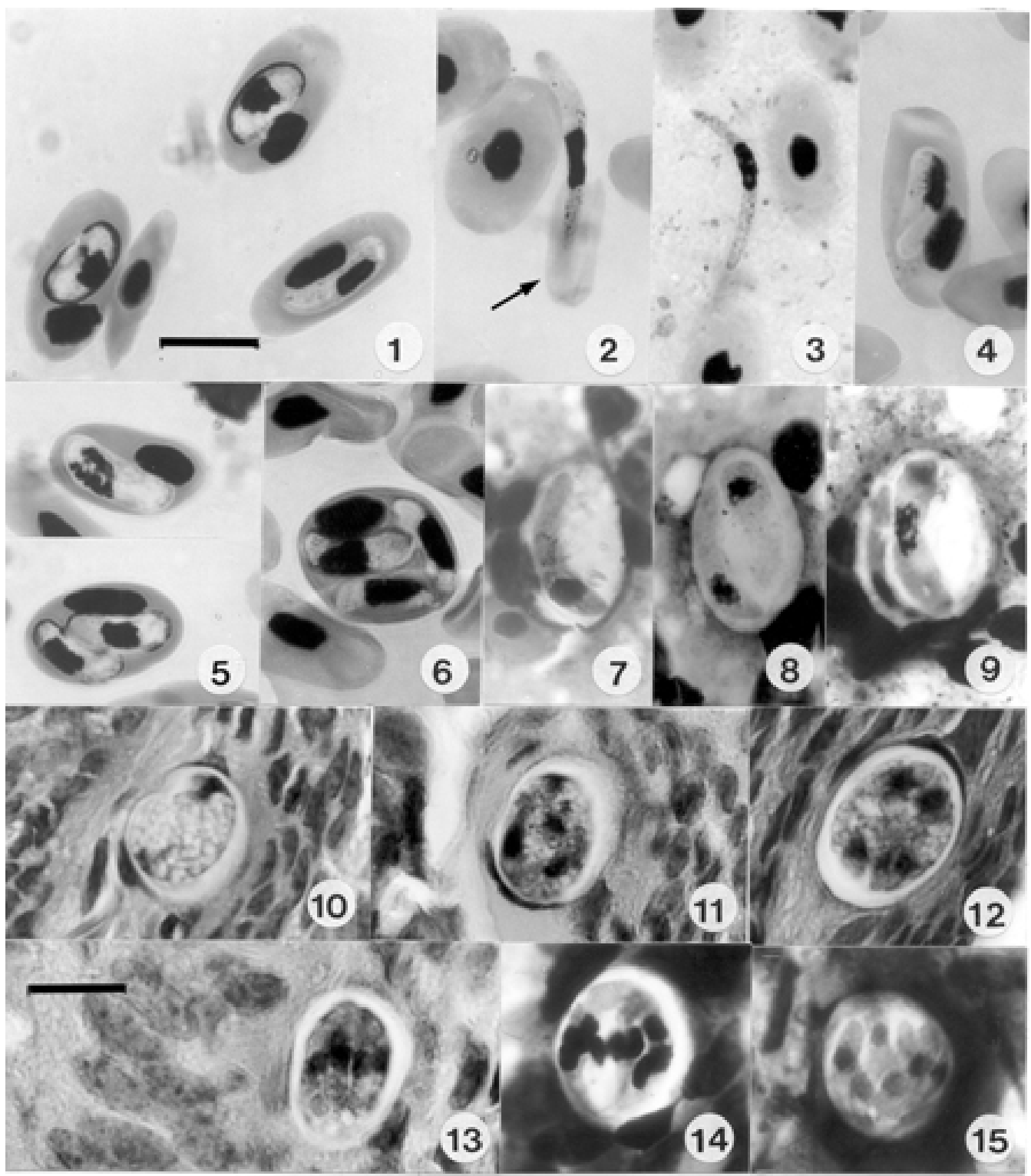

Figs 1-15. Hepatozoon caimani in Caiman crocodilus crocodilus and C. c. yacare. Fig.1: intraerythrocytic gametocytes: two showing conspicuous capsules and another apparently uncapsulated. Figs 2, 3: free gametocytes: one is emerging from its capsule (arrowed). Fig. 4: gametocyte, showing doubling up of the parasite in the erythrocyte. Figs 5, 6: multiple infection of erythrocytes, and a gametocyte with a reticulated nucleus. Figs 7-9: monozoic and dizoic cysts in liver smears. Figs 10-13: developing schizonts in the lamina propria of the ileum of two experimentally infected caimans, 13 and 14 days after these animals were fed with infected mosquitoes. Sections stained with haematoxylin and eosin. Figs 14,15: segmented schizonts, as seen in smears of the small intestine of the same animal, stained by Giemsa's method. Bars $=10 \mu \mathrm{m}$ for all figures 
zoites measured 19-22 x 4-5 (25 measured) and frequently showed conspicuous movements within the sporocyst: freed sporozoites fixed in Bouin's fluid and stained by a modified Giemsa's method measured slightly less, probably due to shrinkage following fixation (Figs 29, 30). The intensely staining nucleus is located more towards the broader and rounded extremity: large but less densely staining masses probably represent the crystalloid inclusions described in the sporozoites of Hepatozoon spp. by various authors (Smith \& Desser 1998).

Both fresh preparations and sections of infected mosquitoes showed development to be remarkably asynchronous. Thus, at 13 d.p.i., single mosquitoes showed a mixture of parasites showing early and late sporoblast formation (Figs 31-34). In most cases sporocysts were fully mature at 21 d.p.i, but in some batches of mosquitoes the sporozoites were incompletely differentiated at 22 d.p.i, possibly the result of temperature fluctuations.

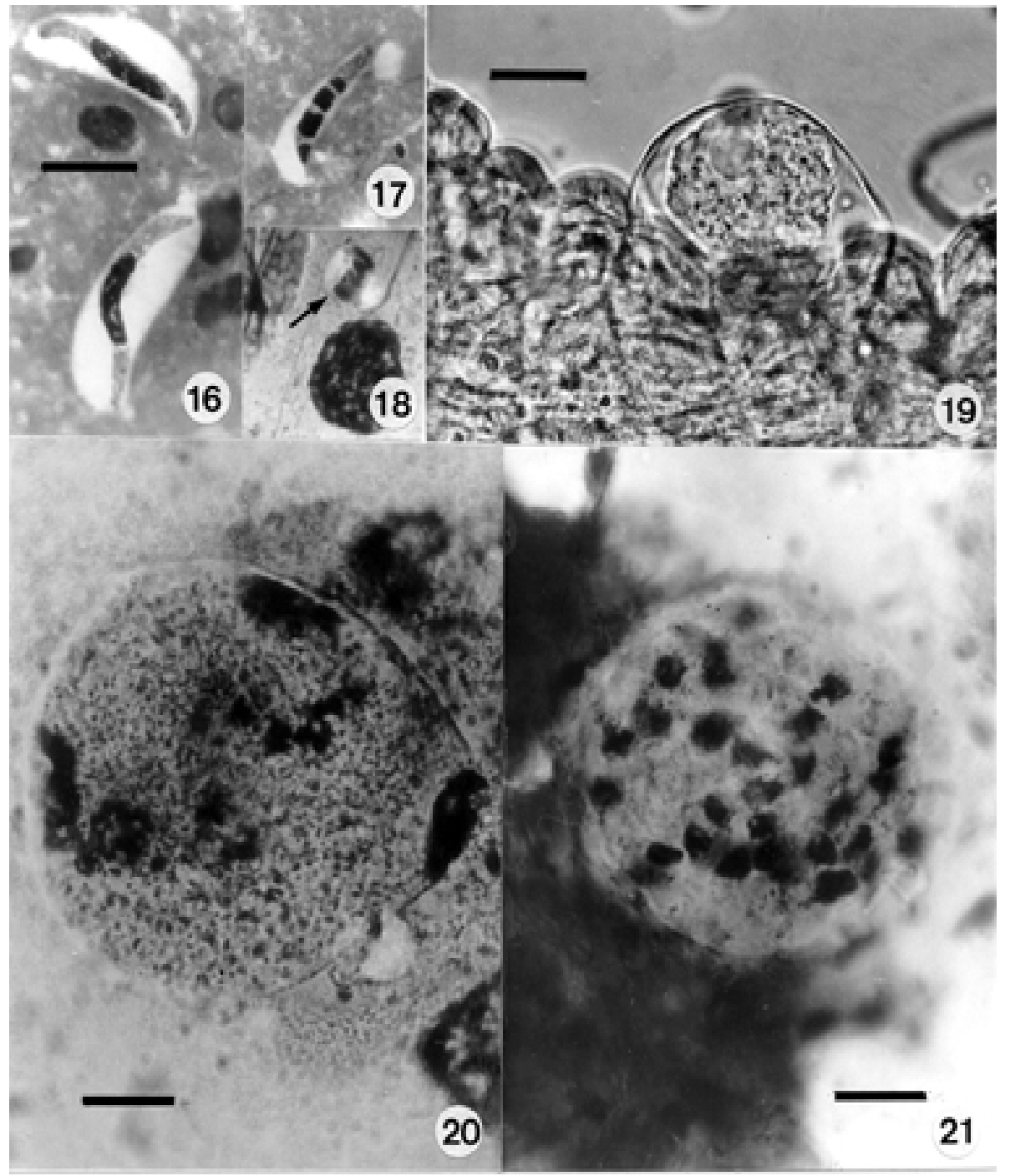

Figs 16-21: development of Hepatozoon caimani in the mosquito Culex fatigans. Fig. 16: freed gametocytes in a Giemsa-stained smear of the intestine and contained blood, $3 \mathrm{~h}$ after the blood-meal. Figs 17,18: elongated and spherical (arrowed) forms with divided nuclei in a smear made $12 \mathrm{~h}$ after the blood-meal. Fig. 19: freshly dissected mosquito gut, 11 days after the blood-meal, showing a uninucleate sporont beneath the elastic membrane on the outer surface of the midgut. Figs 20, 21: giemsa-stained smear of a mosquito gut and contents, 13 days after the blood-meal: early nuclear division of sporonts. Bars $=10 \mu \mathrm{m}$ 
Development in the frogs Leptodactylus fusca and Rana catesbeiana - Monozoic, dizoic and hexazoic cysts were abundant in the liver of $L$. fuscus 28 days after they had been fed with infected mosquitoes (Figs 35-37, 39).

No cysts were detected in the first three $R$. catesbeiana fed with infected mosquitoes at 22 d.p.i. in 1995: almost certainly this was due to the above-mentioned delay in differentiation of sporozoites, as shown in a parallel sample of infected mosquitoes subsequently examined by TEM. Cysts were consistently present, however, in the ten C. catesebiana fed with infected mosquitoes at 23 d.p.i. in 1998 (Figs 38, 40).

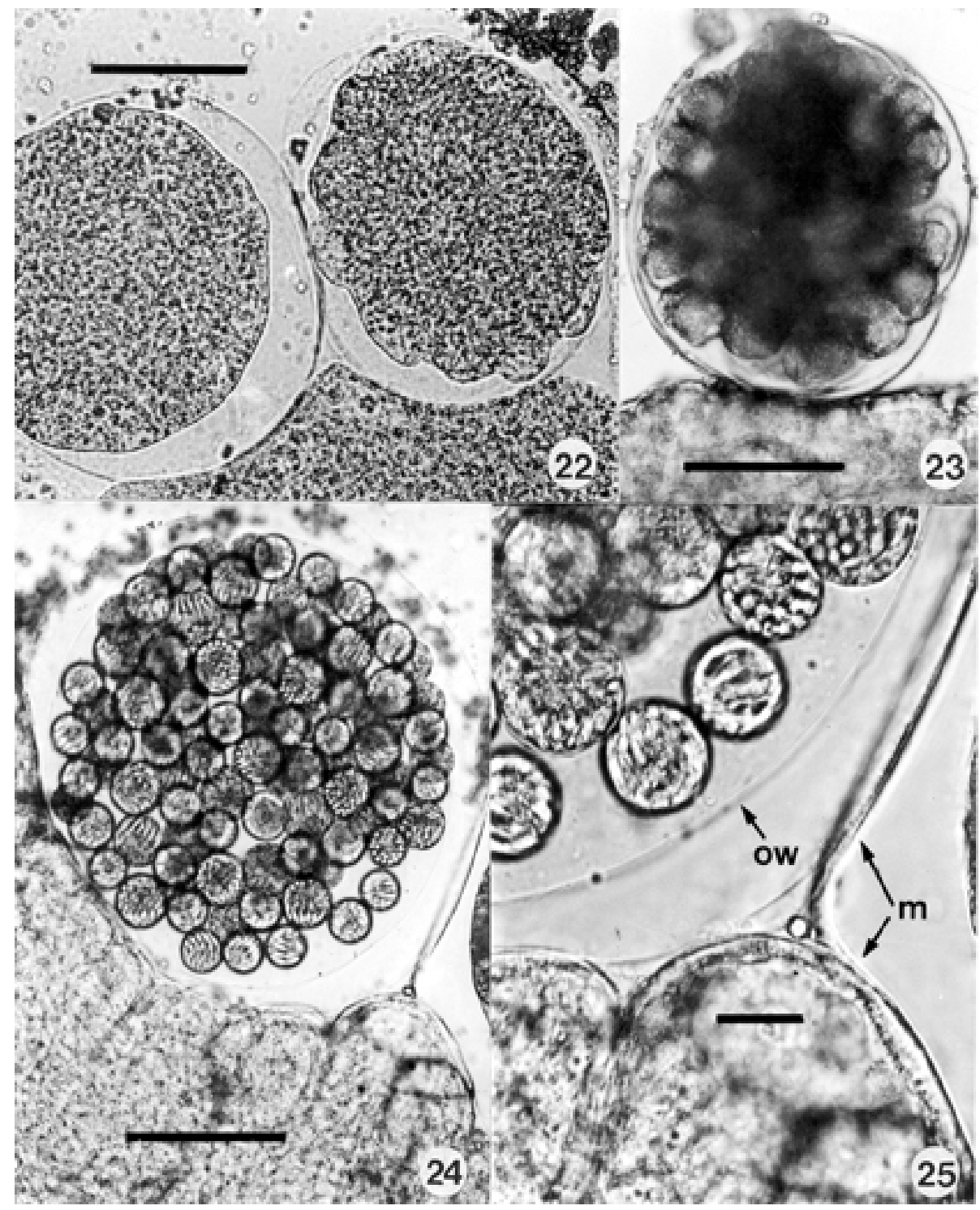

Figs 22-25: development of Hepatozoon caimani in Culex fatigans, as seen in coverslip preparations of freshly dissected mosquitoes. Figs 22, 23: developing elevations of the sporont surface prior to formation of the sporoblasts, 14 days after the blood-meal. Bar $=50 \mu \mathrm{m}$. Fig. 24: mature oocyst on the gut surface, 21 days after the infective blood-meal. Bar $=100 \mu \mathrm{m}$. Fig. 25: enlarged view of the same oocyst, showing its position beneath the stretched elastic membrane on the surface of the midgut (arrowed), ow: oocyst wall; m: membrane of the midgut surface. $B a r=20 \mu \mathrm{m}$ 
Development of the cysts, principally in the liver and less frequently in the lungs and the spleen, appeared to be within the reticulo-endothelial cells. Morphologically they were indistinguishable from those seen in the viscera of naturally infected caimans (Figs 7-9). In fresh liver squashes (Figs 39-41) the cysts are ovoid to spherical bodies measuring $15 \times 10(14.5 \times 12-21 \times 20)$ ( 25 measured). They usually contained one or two slender zoites, very rarely four to six, and a prominant residual body of large spherules. In Giemsa-stained smears (Figs 35-38) the residual body was inapparent, possibly having been destroyed in the process of fixation.
No intraerythrocytic parasites were detected in any of the infected frogs.

Transmission to caimans via cystic stages in the frogs L. fuscus and Rana catesbeiana - One of the wild-caught frogs, $L$. fuscus showing abundant cysts in its liver, was fed to a young, wild-caught caiman in which no haemogregarines could be detected after repeated examination of stained blood films. Gametocytes were detected in its blood just over two months later.

The two C. c. crocodilus sacrificed 13 and 14 days after being fed with infected frogs showed no gametocytes in their blood, but developing and mature schizonts were abun-

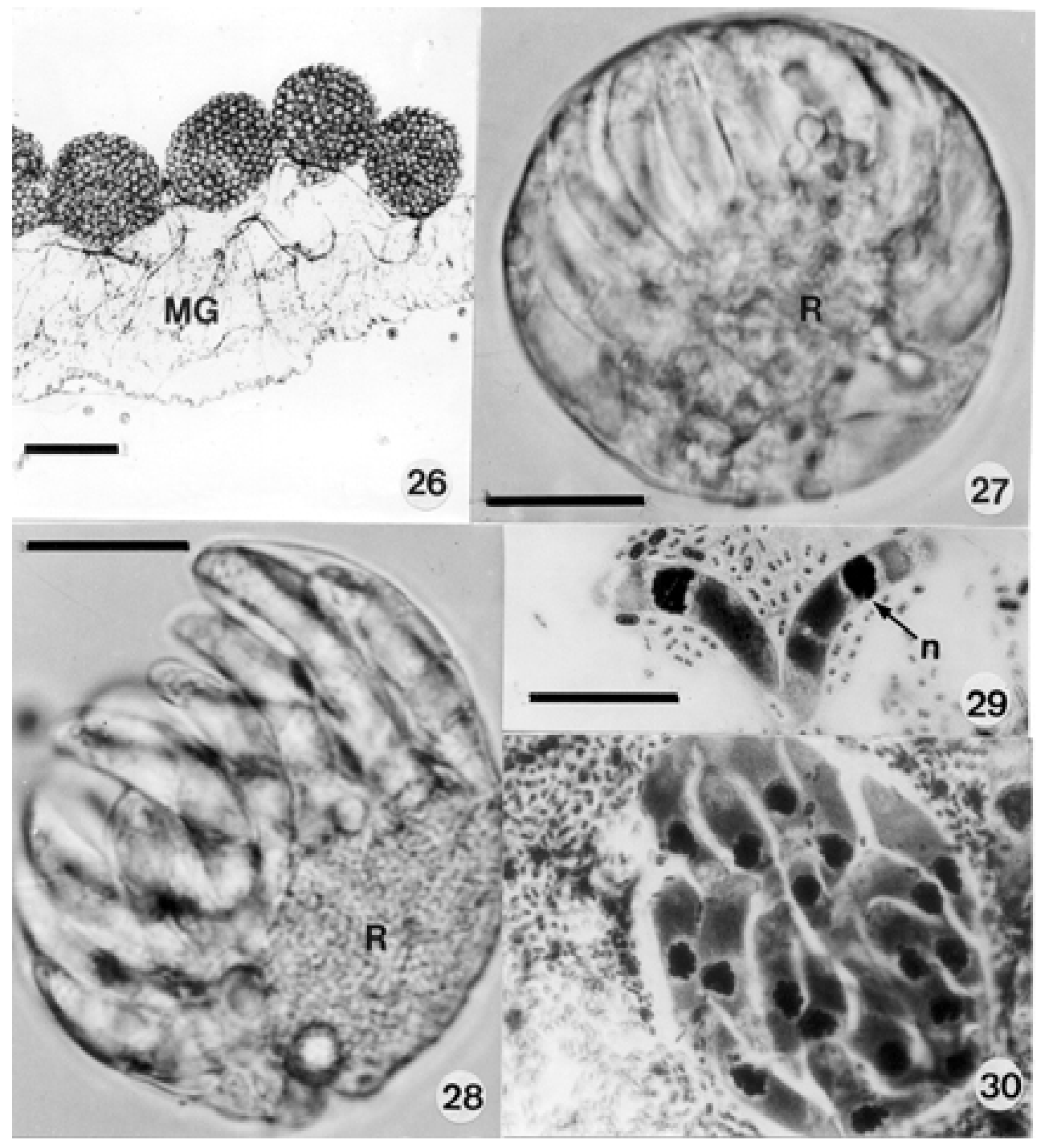

Figs 26-30: development of Hepatozoon caimani in Culex fatigans. Fig. 26: mature oocysts clustered on the gut surface, 21 days after the infective blood-meal. Fresh preparation. Bar $=200 \mu \mathrm{m}$. Figs 27, 28: freed, living sporocysts from a ruptured oocyst, showing sporozoites and prominent sporocystic residuum $(\mathrm{R})$. Bars $=10 \mu \mathrm{m}$. Figs 29, 30: freed, Giemsa-stained sporozoites from a ruptured sporocyst; $\mathrm{n}=$ nucleus. The cluster of sporozoites probably represents the entire contents of a single ruptured sporocyst. Bouin fixation. Bar $=10 \mu \mathrm{m}$ 
dant in the smears and sections of the lamina propria of the small intestine. Young undivided forms possessed a highly vacuolated cytoplasm containing from 2-6 nuclei (Figs 10-13). Segmented schizonts were $15.8 \times 13(13 \times 9.6-$ $20.7 \times 18$ ) as seen in Giemsa-stained smears (Figs 14, 15) and $16.5 \times 12.2(14 \times 14-22.2 \times 11.8)$ in sections ( 25 of each, measured). As far as we could ascertain they produced from 6 to 10 crescentic merozoites measuring approximately $11.2 \times 2(9.6 \times 2.2-16 \times 2.2)$ : the number may have been greater in some schizonts in which some nuclei were super- imposed on others. No schizonts were detected in the liver, spleen, lungs and kidneys of these animals.

The four surviving caimans fed with infected frogs showed no gametocytes in their blood when examined 52 days later, but gametocytes were present in their erythrocytes when they were next examined 79 d.p.i. The prepatent period was, therefore, at some time between 52-79 days.

Transmission to caimans via infected mosquitoes The two C. c. crocodilus fed with infected mosquitoes

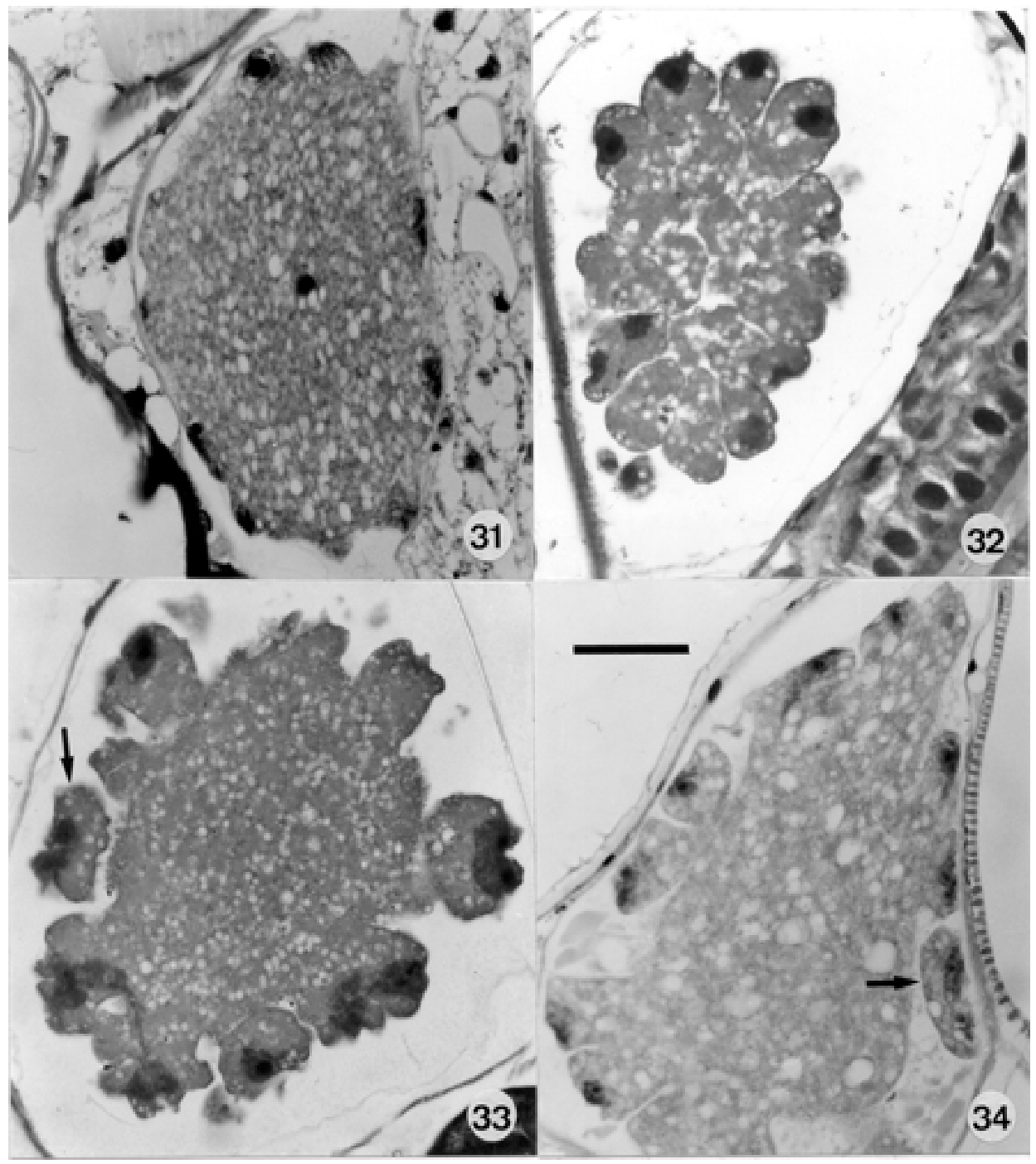

Figs 31-34: asynchronous sporogonic development of Hepatozoon caimani in a single Culex fatigans, 13 days after the blood-meal. Fig. 31: beginning of sporoblast formation. Fig. 32: more advanced stage, with uninucleate sporoblasts almost budded off. Figs 33, 34: separated (arrowed) and separating sporoblasts, with early nuclear division subsequently giving rise to the sporocysts and contained sporozoites. Histological sections stained with haematoxylin and eosin. Bar $=10 \mu \mathrm{m}$ for all figures 


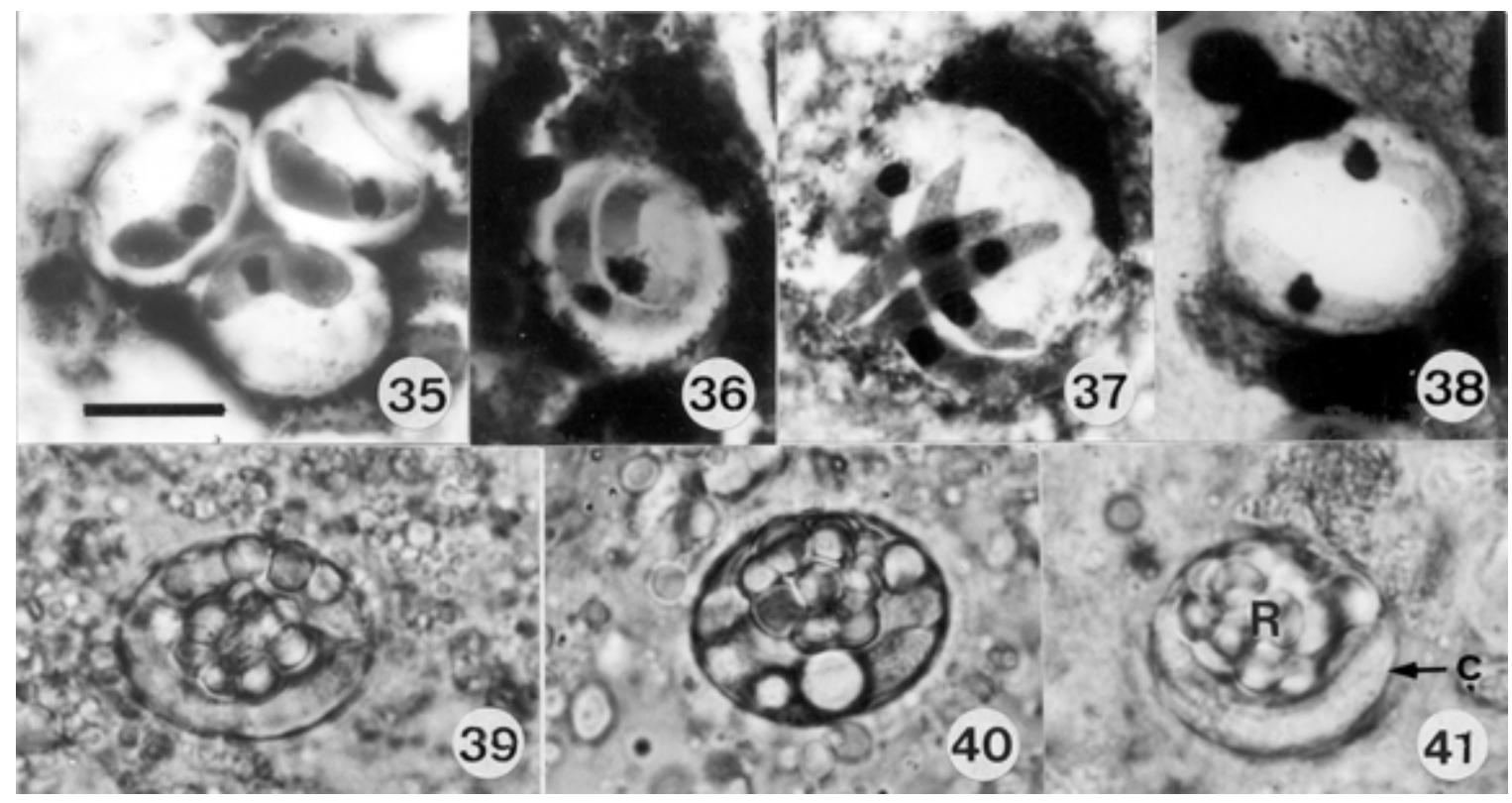

Figs 35-41: resting cystic stages of Hepatozoon caimani in a variety of experimental secondary vertebrate hosts. Figs 35-37: in Giemsastained liver smears of the frog Leptodactylus fuscus: monozoic, dizoic and hexazoic cysts (one cystozoite in the latter is in a different focal plane). Fig. 38: in the frog Rana catesbeiana. Figs 39-41: living cysts in squash preparations of liver from the frogs $L$. fuscus and $R$. catesbeiana and the lizard Neusticurus bicarinata, following their ingestion of infected Culex fatigans; c: cystozoite; R: residual body. Bar $=10 \mu \mathrm{m}$ for all figures

first showed gametocytes in their peripheral blood 82 days later, the prepatent period being somewhere between 5282 days. Monozoic and dizoic cysts, indistinguishable from those developing in frogs and in the viscera of naturally infected caimans, were relatively abundant in smears of the liver, but rare in those of the spleen, lungs and kidneys. No schizogonic stages were detected.

\section{DISCUSSION}

It remains highly probable that most haemogregarines described in crocodilians throughout the world are species of Hepatozoon. We feel, however, that it is unwise to transfer all of those described under the name of Haemogregarina to the genus Hepatozoon until observations have been made on their sporogonic cycle in the invertebrate host. Thus, allocation of the name Haemogregarina crocodilinorum to a haemogregarine of the American alligator by Börner (1901) may have been justified, for Khan et al. (1980) have since described erythrocytic schizogony of a haemogregarine in this crocodilian, and a sporogonic cycle typical of the genus Haemogregarina in leeches removed from wild-caught alligators.

From their very similar morphology and the pattern of their sporogonic cycles, we consider the haemogregarines of $C$. latirostris and C. crocodilus to be conspecific, namely H.caimani (Carini 1909, Pessôa et al. 1972). The haemogregarine of another genus, Melanosuchus niger, has indistinguishable blood forms and a similar sporogonic cycle (Lainson, unpublished observations), which leads us to suggest that all the Hepatozoon species of the Alligatorinae (American caimans and alligators) may, in fact, be H. caimani. Cross-infection experiments and DNA analyses are needed to settle the question as to just how many valid species of the genus exist in crocodilians of both the Old World and the Americas.

In discussing the transmission of $\mathrm{H}$. pettiti of Crocodylus niloticus, Hoare (1932) suggested that this occurred when an infected tsetse fly settles in the open mouth of the crocodile to feed and when the animal, irritated by the bite, “... may snap its jaws and crush the fly, thus liberating the cysts of the haemogregarine in the buccal cavity". We succeeded in transmitting $H$. caimani to clean caimans by feeding them with infected $C$. fatigans and, as newly hatched caimans snap at almost everything that moves, it quite likely includes mosquitoes coming to feed on them. It is notable that many of the infected animals we studied were estimated to be only a few months old.

Landau et al. (1970a, 1970b, 1972) indicated the important role of endogenous cysts located in the tissues of a secondary host in the transmission of Hepatozoon species. In a study of $H$. domerguei of snakes and lizards in Madagascar they described the life-cycle as follows: mature oocysts develop in mosquitoes which have ingested gametocytes during a blood-meal on an infected snake, and the mosquitoes may then be eaten by the lizard host, allowing the released sporozoites to gain entrance into the viscera, principally the liver. Here they become encysted and, by the process of successive endodyogenies, produce from two to six cystozoites. The cysts remain latent in the tissues until the lizard is eaten by the snake predator, when the cystozoites are released and penetrate organs, such as the liver and lungs. In these organs they undergo successive, large-progeny 
schizogonic divisions which eventually complete the cycle by the production of gametocytes which invade the peripheral blood. From our present study we feel that a similar process is the predominant mode of transmission for $H$. caimani.

Whether or not frogs are the major source of cysts of this parasite in nature remains to be determined. During the present studies infected mosquitoes were also fed to specimens of the semi-aquatic teiid lizard Neusticurus bicarinatus and cysts containing from 1-4 cystozoites were later encountered in the liver and lungs of these animals (Fig. 41). Unfortunately, it is uncertain if these cysts were those of $H$. caimani or of another Hepatozoon we have occasionally encountered in the erythrocytes of $N$. bicarinatus, and the sporogony of which has also been followed in $C$. fatigans (Lainson, unpublished observations).

The number of cystozoites produced per cyst seems to vary both with the species of Hepatozoon and within the same species. Monozoic cysts have been recorded for $H$. griseisciuri of squirrels (Desser 1990); both monozoic and dizoic for $H$. balfouri of jerboas (Hoogstraal 1961); dizoic for H. sauromali of the iguanid lizard Sauromalus hispidus (Lewis \& Wagner 1964), monozoic to hexazoic for H. domerguei (Landau et al. 1972) and H. caimani (present investigation), and dizoic to octozoic for H. kisrae of the lizard Agama stellio (Paperna et al. 2002). Cysts containing four or more cystozoites may present problems in their differentiation from mature, primary schizonts, which are of similar size. Prior to maturity, however, the schizonts may be recognised by the presence of several nuclei in the undivided cytoplasm (Figs10-12), whereas in the cysts successive endodyogenies immediately result in a pair, or pairs, of cystozoites. In addition, both sporozoites and cystozoites usually contain prominant crystaloid inclusions (Smith \& Desser 1998), which are absent in merozoites. In the present study, although such inclusions were very conspicuous in Giemsa-stained sporozoites from ruptured oocysts (Fig. 29), they were much less obvious in cystozoites in the tissues of the frogs and caimans (Figs 7-9, 35-38), and Paperna et al. (2002) noted their apparent absence in some cystozoites of $H$. kisrae.

A surprise in our study has been the detection of schizonts only in the lamina propria of two experimentally infected caimans sacrificed at 13 and 14 d.p.i., and our inability to demonstrate schizogonic stages in the liver, lungs, spleen and kidney of eight animals with natural infections of undetermined duration. This, and the failure of other authors to demonstrate schizonts in the viscera of naturally infected caimans (Carini, 1909, Di Primio 1925, Pessôa et al. 1972) suggests that after the penetration of the intestinal epithelium by sporozoites or cystozoites, subsequent schizogony is limited to the lamina propria of the small intestine. It is unfortunate that, in the expectancy that schizonts would be located in the liver, spleen or kidney, we did not examine the intestines of the naturally infected animals. In other species of Hepatozoon, particularly those of snakes, large schizonts, producing many merozoites, are usually abundant in the liver, lungs and other organs.
Both the natural invertebrate vector(s) and the intermediate vertebrate host(s) of $H$. caimani remain to be determined. It may be that a variety of haematophagous arthropods can serve as vectors, for the full sporogony of Hepatozoon spp. has been recorded in experimental or natural infections of $C$. fatigans, $C$. tarsalis, $C$. pipiens and C. territans (Mackerras 1962, Booden et al. 1970, Bashtar et al. 1984, Desser et al. 1995), Aedes togoi and Aedes aegypti (Ball et al. 1969, Lowichik et al. 1993), Anopheles stephensi (Landau et al. 1972), the ticks Argas brumpti and Hyalomma aegyptium (Garnham 1955, Paperna et al. 2002), triatomid bugs (Da Rocha e Silva 1975), a sand fly, Lutzomyia sp. (Lainson, unpublished observation) and the tsetse fly, Glossina palpalis (Hoare 1932). We have found $H$. caimani to develop equally well in C. fatigans and A. aegypti, both of which feed avidly on caimans in the laboratory. Finally, in view of the role of tsetse flies in the transmission of $H$. pettiti in Africa, tabanids must figure in the list of suspects, especially as four different species of these flies have been shown to feed on C. c. crocodilus in Amazonian Brazil (Ferreira et al. 2002). There have been a number of unsuccessful attempts to transmit haemogregarines of both crocodilians and snakes by leeches, although the parasites have on occasions produced sporulated oocysts (Pessôa \& Cavalheiro 1969a, b, Khan et al. 1980, Ball 1958, Smith et al. 1994). These, and our own failure to obtain development of H. caimani in leeches suggests them to be unsuitable vectors of Hepatozoon.

In their description of the development of H. caimani in the mosquito Culex dolosus, Pessôa et al. (1972) recorded the apparent division of the sporont of young oocysts into two "sporoblasts", one of which degenerated while the other completed development in the usual way. We failed to see such division of the sporont and are of the opinion that the two bodies they observed represented two sporonts in close apposition and enclosed by the overlying elastic membrane of the insect stomach. The individual oocyst walls of the two parasites are clearly visible in the Figs 6 and 7 of these authors.

Landau et al. (1972) showed that different genera of lizards and snakes can harbour cysts of $H$. domerguei, and that gametocytes of this parasite circulate in the peripheral blood of both the snake and the lizard hosts, thus greatly facilitating infection of the mosquito vector. Our demonstration of resting cysts of $H$. caimani in two different genera of frogs, Leptodactylus and Rana suggests that, in the same way, there may be a wide range of anuran hosts for $H$. caimani. As far as we are aware there was no development of gametocytes of this parasite in the blood of the experimental frogs. Although Paperna and Smallridge (2001) found that gametocytes of Hemolivia mariae, a haemogregarine of the Australian lizard Tiliqua rugosa, eventually did appear in the blood of lizards of other genera that had been fed with infected tick viscera, it was only after an abnormally long prepatent period. Quite likely, the more drastic move of H. caimani from a reptilian host to an amphibian may entirely preclude the production of gametocytes in frogs.

The possible role of lizards as secondary hosts of the cystic stages of $H$. caimani requires further investiga- 
tion, and our apparent transmission of this parasite to the lizard Neusticurus bicarinatus needs confirmation with laboratory-bred lizards.

As cysts containing cystozoites were readily demonstrable in the tissues of both naturally and experimentally infected caimans, a third route of transmission by cannibalism needs to be considered. Cannibalism appears to be most frequent among juvenile crocodilians of different size in overcrowded conditions (Alderton 1991).

There remain other gaps in our knowledge of the life cycle, in particular the fertilization process in the invertebrate vector. This probably follows a similar pattern to that described by Mackerras (1962) for $\mathrm{H}$. breinli of the Australian lizard Varanus tristis in experimentally infected C. fatigans; namely, association of the male and female gametocytes, production of four flagellated gametes by each microgametocyte, fertilization and the production of the zygotes giving rise to the oocysts. Landau et al. (1972), however, described the microgametocyte of $H$.domerguei as producing only two gametes. Possibly, our failure to find undoubted stages of the fertilization process was because a search for them was not made beyond $12 \mathrm{~h}$ p.i.

If one accepts the hypothesis of co-speciation, which postulates that parasites and their hosts speciate in synchrony (Brooks 1979), the apparent restriction of the schizogony of $H$. caimani to the lamina propria of the small intestine is of particular interest. It suggests that invasion of the liver and other organs in the more evolved vertebrate hosts may have been of secondary development in the evolution of the genus Hepatozoon.

A further paper is to be published on the ultrastructure of the sporogonic stages of $H$. caimani.

\section{ACKNOWLEDGEMENTS}

To Constância M Franco, Manoel C de Souza and Antonio $\mathrm{J}$ de Oliveira Monteiro for technical assistance. Dr Marcia CC Valuti Centeno of the "Rãmazon" frog farm kindly provided the frogs bred in captivity, and Dr Jorge AA Monteiro, of the "Crocodile Safari" Zoological Gardens, the young caimans. Histological sections were prepared by Marina Schein, Department of Animal Sciences, Rehovot (Figs 31-34) and Walter M Campos, Instituto Evandro Chagas (Figs 10-13).

\section{REFERENCES}

Alderton D 1991. Crocodiles and Alligators of the World, Blandford Publishing, England, 190 pp.

Ball GH 1958. A haemogregarine from a water snake, Natrix piscator taken in the vicinity of Bombay, India. J Protozool 5: 274-281.

Ball GH, Chao J, Telford SR 1969. Hepatozoon fusifex sp.n. a haemogregarine from Boa constrictor producing marked morphological changes in infected erythrocytes. J Parasitol 55: 800-813.

Bashtar AR, Ghaffar FA, Mehlhorn H 1984. Hepatozoon aegypti nov.sp. 3. Electron microscope studies on the gamonony and sporogony inside the vector, Culex pipiens molestus. Z Parasitenkund 70: 53-65.

Booden T, Chao J, Ball GH 1970. Transfer of Hepatozoon sp., from Boa constrictor to a lizard, Anolis carolinensis, by mosquito vectors. J Parasitol 56: 832-833.

Börner C 1901. Untersuchungen über Hämosporidien. I. Ein Beitrag zur Kenntnis des genus Haemogregarina Danilewsky. Z Wiss Zool Abt A 69: 398-416.
Brooks DR 1979. Testing the context and extent of host-parasite coevolution. Syst Zool 28: 299-307.

Carini A 1909. Sur une hémogrégarine du Caiman latirostris Daud. Bull Soc Pathol Exot 2: 471-472.

Chatton E, Roubaud E 1913. Sporogonie d'une hémogrégarine chez une tsétsé (Glossina palpalis R. Desv.). Bull Soc Path Exot 6: 226-233.

Da Rocha e Silva EO 1975. Ciclo evolutivo do Hepatozoon triatomae (Sporozoa,Haemogregarinidae) parasita de triatomíneos. Rev Saúde Públ São Paulo 9: 383-391.

Di Primio R. 1925.Contribuição para o conhecimento das haemogregarinas do Brasil. Sciencia Méd 3: 574-576.

Desser SS 1990. Tissue "cysts" of Hepatozoon griseisciuri in the grey squirrel, (Sciurus carolinensis Gmelin, 1788), with studies on the life cycle. J Parasitol 76: 257-259.

Desser SS, Hong H, Martin DS 1995. The life history, ultrastructure, and experimental transmission of Hepatozoon catesbianae n. comb., an apicomplexan parasite of the bullfrog, Rana catesbeiana and the mosquito Culex territans in Algonquin Park, Ontario. J Parasitol 81: 212-222.

Ferreira RLM, Henriques AI, Rafael JA 2002. Activity of tabanids (Insecta: Diptera: Tabanidae) attacking the reptiles Caiman crocodilus (Linn.) (Alligatoridae) and Eunectes murinus (Linn.) (Boidae), in the Central Amazon, Brazil. Mem Inst Oswaldo Cruz 97: 133-136.

Garnham PCC 1955. A haemogregarine infection in Argas brumpti. Trans R Soc Trop Med Hyg 49: 9.

Hoare CA 1932. On protozoal blood parasites collected in Uganda, with an account of the life cycle of the crocodile haemogregarine. Parasitology 24: 210-224.

Hoogstraal H 1961. The life cycle and incidence of Hepatozoon balfouri (Laveran, 1905) in Egyptian jerboas (Jaculus spp.) and mites (Haemolaelaps aegyptius Keegan, 1956). J Protozool 8: 231-248.

Khan RA, Forrester DJ, Goodwin TM, Ross CA 1980. A haemogregarine from the American alligator (Alligator mississippiensis). J Parasitol 66: 324-328.

Lainson R 1977. Trypanosoma cecili $\mathrm{n}$. sp., a parasite of the South American cayman Caiman crocodilus crocodilus (Linnaeus, 1758) (Crocodilia: Alligatoridae). In EU Canning, Protozoology, Vol III, Clunbury Cottrell Press, Berkhampstead, p. 87-93.

Landau I, Chabaud AG, Michel JC, Brygoo ER 1970a. Mise en évidence d'un double mode de transmission chez un Hepatozoon de reptiles malgaches. C R Acad Sc Paris Sér. D, 270: 2308-2310.

Landau I, Chabaud AG, Michel JC, Brygoo ER 1970b. Données nouvelles sur le cycle évoltif d'Hepatozoon domerguei: importance de l'endogénèse; analogies avec d'autres cycles de Coccidies. C R Acad Sc Paris Sér. D, 271: 1679.

Landau I, Michel JC, Chabaud AG 1972. Cycle biologique d'Hepatozoon domerguei; discussion sur les caractères fondamentaux d'un cycle de Coccidie. Z Parasitenk 38: 250-270.

Levine ND 1988. The Protozoan Phylum Apicomplexa. Vol II, CRC Press Inc., Boca Raton, Florida, 203 pp.

Lewis JE, Wagner ED 1964. Hepatozoon sauromali sp.n., a haemogregarine from the chuckwalla (Sauromalus spp.) with notes on the life history. J Parasitol 50: 11-14.

Lowichik A, Lanners HN, Lowrie RC, Meiners NE 1993. Gametogenesis and sporogony of Hepatozoon mocassini (Apicomplexa:Adeleina: Hepatozoidae) in an experimental mosquito host, Aedes aegypti.J Euk Microbiol 40: 287297.

Mackerras MJ 1962. The life history of a Hepatozoon (Sporozoa:Adeleidea) of varanid lizards in Australia. Aust J Zool 10: 35-44. 
Paperna I, Smallridge CJ 2001. Ultrastructure of developmental stages of Hemolivia mariae (Apicomplexa: Haemogregarinidae), natural parasite of the Australian sleepy lizard, in experimentally infected deviant hosts. Folia Parasitol 48: 225-262.

Paperna I, Kremer-Mecabell T, Finkelman S 2002. Hepatozoon kisrae n. sp. infecting the lizard Agama stellio is transmitted by the tick Hyalomma cf. aegyptium. Parasite 9: 17-27.

Pessôa SB, Cavalheiro J 1969a. Notas sobre hemogregarinas de serpentes Brasileiras. VIII. Sobre a evolução da Haemogregarina miliaris na sanguessuga Haementeria lutzi. Rev Bras Biol 29: 451-458.

Pessôa SB, Cavalheiro J 1969b. Notas sobre hemogregarinas de serpentes Brasileiras. IX. Sobre a hemogregarina da Helicops carinicauda (Wied). Rev Goiana Méd 15: 161168.

Pessôa SB, De Biasi P, De Souza D 1972. Esporulação do Hepatozoon caimani (Carini,1909), parasita do jacaré-depapo-amarelo: Caiman latirostris Daud, no Culex dolosus
(L. Arribálzaga). Mem Inst Oswaldo Cruz 70: 379-383.

Siddall ME 1995. Phylogeny of adeleid blood parasites with a partial systematic revision of the haemogregarine complex. J Euk Microbiol 42: 116-125.

Smith TG 1996. The genus Hepatozoon (Apicomplexa: Adeleina). J Parasitol 82: 565-585.

Smith TG, Desser SS 1998. Ultrastructural features of cystic and merogonic stages of Hepatozoon sipedon (Apicomplexa: Adeleorina) in northern leopard frogs (Rana pipiens) and northern water snakes (Nerodia sipedon) from Ontario, Canada. J Euk Microbiol 45: 419-425.

Smith TG, Desser SS, Martin DS 1994. The development of Hepatozoon sipedon n.sp. (Apicomplexa: Adeleina: Hepatozoidae) in its natural host, the Northern water snake (Nerodia sipedon sipedon), the culicine vectors, Culex pipiens and Culex territans, and an intermediate host, the Northern leopard frog (Rana pipiens). Parasitol Res 80: 559-568.

Wenyon CM 1926. Protozoology Vol II, William Wood and Company, NewYork, 1396 pp. 